\title{
Anne-Sophie Lamine (dir.), Quand le religieux fait conflit. Désaccords, négociations ou arrangements
}

Rennes, Presses Universitaires de Rennes, coll. " Sciences des Religions », 2013, $240 \mathrm{p}$.

\section{Maixant Mebiame Zomo}

\section{(2) OpenEdition}

Journals

Édition électronique

URL : http://journals.openedition.org/assr/26478

DOI : $10.4000 /$ assr. 26478

ISSN : $1777-5825$

Éditeur

Éditions de l'EHESS

Édition imprimée

Date de publication : 31 décembre 2014

Pagination : 233

ISBN : 978-2-7132-2467-6

ISSN : 0335-5985

Référence électronique

Maixant Mebiame Zomo, « Anne-Sophie Lamine (dir.), Quand le religieux fait conflit. Désaccords, négociations ou arrangements", Archives de sciences sociales des religions [En ligne], 168 | 2014, mis en ligne le 30 avril 2015, consulté le 22 septembre 2020. URL : http://journals.openedition.org/assr/ 26478 ; DOI : https://doi.org/10.4000/assr.26478

Ce document a été généré automatiquement le 22 septembre 2020.

() Archives de sciences sociales des religions 


\section{Anne-Sophie Lamine (dir.), Quand le religieux fait conflit. Désaccords, négociations ou arrangements}

Rennes, Presses Universitaires de Rennes, coll. « Sciences des Religions », 2013, 240 p.

Maixant Mebiame Zomo

\section{RÉFÉRENCE}

Anne-Sophie Lamine (dir.), Quand le religieux fait conflit. Désaccords, négociations ou arrangements, Rennes, Presses Universitaires de Rennes, coll. « Sciences des Religions », 2013, 240 p. 
1 Cet ouvrage collectif s'inscrit dans le cadre du projet de recherche ANR (Agence nationale de la recherche) intitulée « La pluralité religieuse enjeu de conflits : de la concurrence des mémoires aux nouveaux usages des identités » (2007-2011). Il aborde un objet très peu appréhendé en sciences sociales : la conflictualité liée à la pluralisation religieuse. Par comparaison avec d'autres formes de conflits sociaux (grève, manifestations), les auteurs soulignent la «dangerosité » des guerres de religion qui menacent encore la cohésion des sociétéscontemporaines.

2 L'ouvrage souligne que le conflit comportant une dimension religieuse se joue à trois niveaux. Le premier concerne la régulation publique du religieux, des conflits dont le règlement engage la

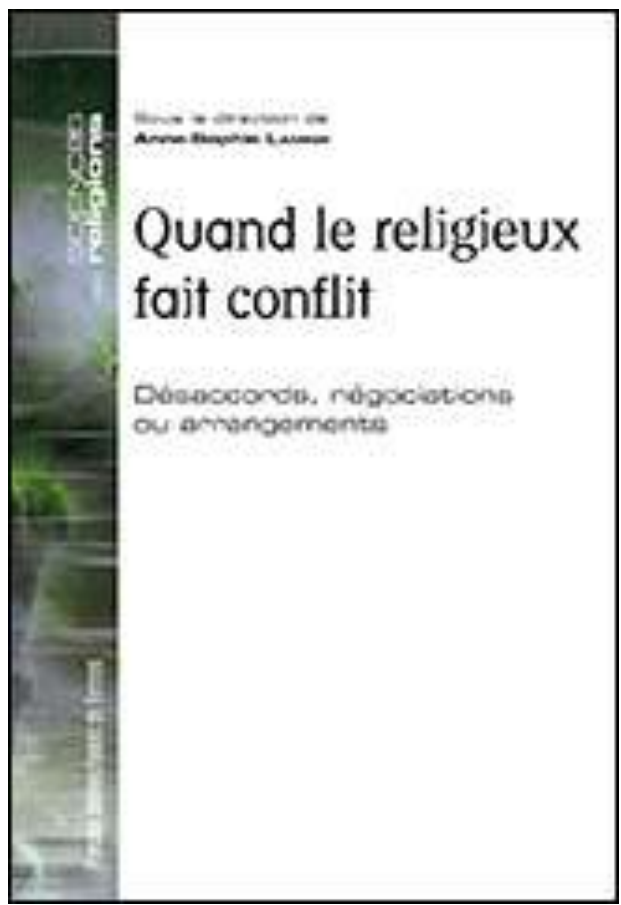
société, une commune ou un établissement public. Mais cette régulation peut aussi concerner les frontières du religieux lorsqu'il s'immisce dans d'autres sphères. Le second niveau porte sur les conflits entre groupes, donc conflits interreligieux ou plus largement conflits interethniques ou interconvictionnels. Enfin, le troisième niveau concerne la conflictualité interne aux groupes, qu'il s'agisse de courants en concurrence ou de conflits sur des pratiques et des dogmes. Ces trois niveaux sont plus ou moins intriqués, selon les configurations. Il s'agit entre autres d'une lecture inédite et analytique de ces antagonismes en s'appuyant sur une série d'enquêtes dans des lieux aussi variés que des prisons, des collèges, des mosquées, des églises pentecôtistes ou des cimetières, sur des pratiques aussi diverses que l'alimentation, le judéo-bouddhisme, les arts martiaux ou la vente directe. Les observations sont menées à des échelles variées : des relations intergénérationnelles à l'État, en passant par la commune, les services publics ou les communautés religieuses. Quelques contrepoints décalent la perspective en sortant de l'Hexagone. Le regard sociologique éclaire ici les modes de régulation et de négociation et révèle l'existence de nombreuses possibilités de compromis et d'ajustement.

L'argumentaire général repose sur une structuration en quatre parties qui réunissent près de quatorze contributeurs. La première partie de l'ouvrage traite des rapports entre pouvoirs politiques et religions. Les auteurs (F. Lorcerie, C. Donnet et J. F. Husson) montrent comment les pouvoirs publics nationaux et locaux régulent le religieux. Cette régulation ne se limite pas au droit. Les pouvoirs publics influencent le choix des interlocuteurs légitimes, la production de discours normatifs, notamment sur le religieux dangereux et le religieux acceptable. Les exemples sur la politisation de l'islam (F. Lorcerie) et la manière dont les musulmans de France deviennent un enjeu électoral, à la fois pour les voix dont ils sont porteurs et pour le traitement de la question. L'islam de France oscille entre altérité radicale (considérée comme menaçant la laïcité et l'identité nationale) et inclusion d'une religion comme une autre. On observe aussi une concurrence entre organisations musulmanes (C. Donnet) face à des 
pouvoirs locaux exerçant leur pouvoir de normalisation par le recours à «l'islam civil ».

4 La deuxième partie de l'ouvrage relate les ajustements nécessaires lorsque le religieux s'invite dans des établissements et des services publics. Les auteurs (R. Sarg, D. Bouzar, C. Vivarelli, I. Becci et B. Knobel) de cette partie se sont résolument inscrits dans une perspective pragmatique. Les auteurs sont attentifs aux modalités de ces conflits, à leur temporalité, aux acteurs en présence, l'interventionnisme d'un tiers, les compromis et les ajustements. Dans les prisons par exemple (R. Sarg), on observe des conflits entre détenus, avec l'institution carcérale et entre aumônerie (catholique, musulmane, protestante et juive). Cette conflictualité qui résulte de la cohabitation interculturelle en cellule se manifeste par des interruptions de prières par des surveillants ou encore de la demande d'un régime alimentaire sans porc. L'institution met en place divers types d'ajustements, spécifiques ou non à la pratique religieuse. Comment la municipalité facilite-t-elle l'enterrement des croyants musulmans sur place (plutôt que le rapatriement dans les pays d'origine) et pallie la désertion des cantines (D. Bouzar). En milieu scolaire, quels types de solutions apporte le pouvoir local à la question de fêtes religieuses, de pratique de sport pendant le ramadan ou encore des signes religieux ostentatoires des parents accompagnant les sorties (C. Vivarelli).

5 Les contributions (C. Rodier, M. Niculescu, H.-Y. Kim et S. Fath) qui forment la troisième partie de cet ouvrage nous renseignent sur la conflictualité inhérente à la diversité interne des groupes religieux et entre religions. Les auteurs nous rappellent que la visibilité du religieux dans l'espace public ne doit pas nous faire ignorer le conflit qui traverse les organisations religieuses et celui qui les oppose à d'autres religions.

6 Les contributions de la quatrième partie du livre (Y. Illy, N. Luca et M. Balas) s'interrogent sur les frontières du religieux qui révèlent en même temps les frontières symboliques d'une société. L'idée est que les activités non religieuses comme le sport à l'exemple des arts martiaux examinés sont des analyseurs de ces frontières. En effet, ces sports traditionnels valorisent le développement spirituel de l'individu et le rapport maitre-disciple. Ce qui les place en porte-à-faux avec le processus de rationalisation et de standardisation des pratiques sportives. C'est aussi le cas de la « vente directe » des entreprises multiniveaux où les conflits résultent de l'attitude de certains vendeurs visà-vis des distributeurs qu'ils recrutent notamment lorsque la dimension de rêve et d'enthousiasme dépasse le seul cadre d'emploi.

7 Le lecteur ne peut terminer sa lecture sans s'arrêter sur l'importante conclusion d'Anne-Sophie Lamine sur les théories du conflit, de la violence du religieux et surtout les stratégies de compromis, d'ajustement et de dialogue intra religieux, interreligieux et avec les pouvoirs locaux de régulation et d'encadrement du religieux et de définition de la "religion correcte ». Pris dans son ensemble, cet ouvrage nourrit la réflexion sur la question du conflit et des formes de "violences" à caractère religieux qui s'observent dans les contextes culturels étudiés et les religiosités en présence. En somme, les thèmes abordés par les auteurs de ce collectif, bien qu'inspirés par leur contexte sociétal d'investigation, touchent à des questions qui dépassent largement ces frontières géographiques. 